\title{
Network Mutual Assistance: A New Model of Personal Life Risk Sharing
}

\section{Based on Internet}

\section{- Thinking Based on the Mutual assistance of Water Drop}

Lili Chen ${ }^{1, a}$

${ }^{1}$ Oxbridge College, Kunming University of Science and Technology, Kunming City, Yunnan Province, 650000 , China

aemail:

Keywords: Network cooperation; Internet; Personal life risk; Risk sharing; Insurance

\begin{abstract}
Network mutual assistance is a new mutual assistance mode. At present, there are a number of network mutual assistance platforms being established, and the main operating mechanism and development models have received widespread attention. Starting from the difference between mutual assistance and mutual insurance, this paper firstly analyzed the connotation of network cooperation, and then compared the network of mutual assistance and mutual insurance, the relation and difference between other Internet financial innovations, and finally put forward the future development path of the mutual assistance network platform.
\end{abstract}

\section{Introduction}

On October $28^{\text {th }}, 2015$, the CIRC issued the risk on the "'mutual assistance plan'" and other types of insurance activities and pointed out that mutual assistance plan is similar to mutual insurance; there are many differences between mutual assistance and mutual insurance in terms of subject qualification, management principle, legal supervision and so on. Network mutual assistance and mutual insurance are similar in launching model, operation mechanism, claim settlement and so on. It is easy to confuse users. The number of current network mutual assistance platforms has reached to over 50, including Water Drop Mutual Assistance, E-mutual Assistance, Anticancer Commune, House Lizard Mutual Assistance and so on. In the Mutual Insurance Companies, there are currently only three mutual insurance companies approved by Chinese Insurance Regulatory Commission. Taking Water Drop Mutual Assistance as an example, it is a mutual assistance charity community. Users can apply for health benefits if they get illness. Water Drop Mutual Assistance is a free fee fundraising tool to provide free services for patients who have difficulties to raise funds, which has thousands of patients with serious illness to get the money. Water Drop entrepreneurial team has won the Joint Angel investment(RMB 50 million) from the Tencent, IDG capital and others. As a new model of personal risk sharing, its operation mechanism and development model has received extensive attention. There are similarities between the operation mechanism of the network of mutual assistance and mutual insurance in the launch mode and claims settle etc. Based on this, this paper carried the related question, and proposed the future development path of the network mutual assistance platform.

\section{Connotation Analysis of Network Cooperation}

There are two innovations through using the Internet n network platform for mutual matching 
function. First, it is exchange risk agreement, which is similar to mutual insurance system. That is, instead of legal entity, the members undertake the risk loss of each other through agreement and commitment. Second is the total amount of individual risk control, such as a single mutual assistance is not more than 3 yuan; thus, the burden of individual individuals is avoided, and the solvency of the individual is avoided. However, the traditional insurance system to determine the duration of the insured requires strong systematic risk control capability.

This model is not unique in the history of insurance development, which is the original form of insurance. The mode of charging is equivalent to the 'class assignment system' on the textbook. Because the efficient interaction of the Internet greatly enhances the efficiency of the expansion of membership and payment collection, so it has more vitality.

Compared with other Internet financial innovations, Network mutual assistance is the combination of Crowdfunding'", '"P2P'" and the insurance industry. Its basic concept and operation model are identical, and social benefits are very prominent, which can be an effective complement to the commercial insurance system. Because the smaller and scattered capital characteristics with interest for the purpose of motivation orientation, the risk is completely controllable. At present, the regulatory has fully recognized the Crowdfunding and P2P model. Therefore, if network cooperation was properly guided, it can completely become a new model in the field of financial insurance innovation.

\section{Comparison and Analysis of Network Mutual assistance}

The difference between network mutual assistance and mutual insurance. In the aspect of raising funds, mutual insurance companies generally take full responsibility to build the regular payment of funds and make special operations. However,mutual assistance funds do not belong to the platform . This can not only avoid policy risks, but also reduce mutual assistance contributions. In the aspect of fund management, mutual insurance funds are distributed by insurance companies to obtain profits, and investment income is used to supplement insurance payment expenses. The network platform for collected mutual funds by the third party hosting platform, do not directly participate in the management in order to prevent the misappropriation of hoarding behavior. In the aspect of supervision, mutual insurance companies and other mutual insurance organization will be included in the CIRC's regulatory scope, and joint-stock insurance companies are supervised by the regulatory policy of the CIRC. The network mutual assistance platform has not been included in the insurance supervision system in the existing framework, mainly relying on platform self-discipline. In terms of risk pricing, mutual assistance plan for networks have not yet been priced at risk, and there is no specific technique for mutual assistance. Mutual insurance business is clear, and the degree of risk homogenization is high, and the scale of members meets the basic requirements of the large number rule. As a result, mutual insurance companies are more specialized in risk pricing and other pricing aspects.

Similarities and differences between mutual assistance platform and other Internet financial innovation. In the operation mode and basic concept, network mutual assistance and Crowdfunding and P2P are very close. They have individual and decentralized characteristics. In this way, risk can be well controlled, and more low-income people can be guaranteed. Social benefits are very outstanding. But there are some differences between network assistance and Crowdfunding and P2P. Crowdfunding means to concentrate on everyone's strength to do something, and mutual assistance refers to assistance each other. In the network mutual assistance platform, it adopts the public raising way to realize mutual guarantee based on the Internet platform. 
At the same time, it achieves the effect of P2P with disintermediation.

\section{Analysis of the Future Development Path of Mutual Help Platform}

Future development through a mode of network mutual assistance platform. The current development of China's network cooperation platform is not very mature. The authenticity of mutual aid events, mutual funds management, mutual assistance platform supervision are still remaining to be improved. But the impact of mutual assistance organizations on society can not be ignored. It provides a new way to avoid risks and is accepted by most people because of their low personal contributions. Therefore, the mutual assistance network platform has its advantages and uniqueness. In the near future, we could expect that the regulatory will issue special necessary supervision measures to ensure the standardized operation of mutual assistance platforms. The network mutual assistance platform will be more mature, and will inject new vitality for the rapid development of China's insurance industry.

Mutual assistance is the basic element in the development of human society, and insurance is only a form of mutual assistance. When it comes to the Internet, people come up with words like "convenient, efficient, inclusive". The network represents science and technology. The combination of network and cooperation should be explored more in order to improve the general welfare of the advanced mode. The author believed that the way the mutual assistance network is to make fully use of big data block chain technology, take advantage of the integration of resources, make more efficient allocation of resources and reduce the cost of platform operation. Network cooperation is an area where insurance has not been paid enough attention or is not easy to be realized, so that to become a useful complement to insurance companies and a multi-level social security system.

Insurance is a risk management method of risk transfer. The loss sharing is achieved by assembling risk units. In insurance activities, the insurer sells insurance products and policyholders buy insurance products, which is a commodity exchange activity. What is exchanged here is a kind of risk protection service. The insured gets the risk protection service by paying premium, and the insurer collects the insurance premium by providing the risk protection service. This reflects a kind of commodity economic relation of price exchange, and its products and services are relatively simple. In contrast, network cooperation can explore more comprehensive risk management tools. To provide more comprehensive services, the resources associated with the "mutual assistance plan" will be integrated into the network platform to become a node in the network system. With the help of information sharing mechanism, the resources of different nodes can be optimized under the platform of organization and management. For example, the network platform associated with mutual protection plans in the implementation process can provide a series of services and health guidance to "mutual assistance plan" members through the upstream and downstream resources in the field of health, which is better than just giving a certain amount of money when you're sick. By taking effective intervention to reduce the incidence of members, this is simply a post compensation sense for members to enjoy a more healthy life. Only in this way can we highlight the value of the network platform: ordinary people at a reasonable cost can enjoy the dignity of the service through the power of the platform, which also can include insurance services. Therefore, the mutual assistance network is not the mutual insurance, but integrating service resources including insurance to create a modern mutual mode through using their own advantages. Only the creation of unique value, the mutual assistance network can get considerable development.

Transforming into purely public welfare organizations. Pure commonwealth organization is similar to "Red Cross", "charitable fund" and other charitable institutions, which do not need to join 
the provisions of the cost sharing approach. In this issue, once the occurrence of major illness or accident, everyone can choose whether to donate. In addition, the form of donation and the amount of donation are not specified. The scope of protection, insurance period, mutual insurance and mutual assistance network are different from each other. Anticancer community is similar to this kind of organization. So pure commonwealth organization is one of future development path for the mutual assistance network platforms. At present, the supervision of pure public welfare organization is paid more and more attention. In 2016, the two sessions of the State Council proposed amendments to the draft "charity law", such as laws of individuals can not publicly collect donations, the right of public offering of charitable organizations has been gradually released, banned the mandatory assessment, fund-raising proposals, the relevant acts of charity norms. Therefore, the transformation into a pure public welfare organization has become a safe and reliable development path of network mutual assistance platform under the supervision of relevant laws and regulations.

\section{Summary}

The research on the path of future development of the mutual assistance network platform helps to discuss the direction of development of mutual insurance market in China. Whether as a network of mutual assistance platform model continues to develop in depth, or transform to mutual insurance companies or to public organizations, study on the development path of the mutual assistance network platform has far-reaching significance under the condition that the relevant regulatory measures can effectively protect their operating standards.

\section{References}

[1] Wei Li, Wang Ying. The Mutual Assistance is Not Suitable for Mutual Insurance[J]. Chinese Finance, 2017, (04): 66-67.

[2] Li Lijuan. Crime and Punishment of Network Assistance[J]. Corporation, 2016, (12): 32-34.

[3] Hu Qi. Operation Model and Future Development Path of Network Mutual assistance Platform[J]. Shanghai Insurance, 2016, (05): 43-45.

[4] Liu Hui, Wen Xu, Wu Xiuzhen, Zhang Xiaojun. Construction and Model of Mutual Information Platform for Rare Diseases[J]. Journal of Medical Informatics, 2013, (03): 35-38.

[5] Tian Kunyue. The Extension of Tourism Mode -- Network Mutual assistance Tourism[J]. Resource Development and Marketing, 2008, (10): 958-960.

[6] Wang Yunliang. The Idea of Network Mutual Travel and the Establishment of Mutual Tourism Network[J]. Economic Geography, 2007, (05): 877-880.

[7] Zheng Tingyou. Study on the Construction of Psychological Assistance Network Platform for College Students[J]. Education and Profession, 2007, (08): 92-94. 